\title{
Identification and Characterization of 1,2-BN Cyclohexene using Microwave Spectroscopy
}

\author{
Stephen G. Kukolich ${ }^{\mathrm{a}, \mathrm{g}}$, Ming Sun $^{\mathrm{b}}$, Adam M. Daly ${ }^{\mathrm{c}}$, Wei Luo ${ }^{\mathrm{d}}$, Lev N. Zakharov ${ }^{\mathrm{e}}$, and Shih- \\ Yuan Liu $^{\dagger}$ \\ ${ }^{a}$ Department of Chemistry and Biochemistry, University of Arizona, Tucson, Arizona 85721, \\ United States \\ ${ }^{\mathrm{b}}$ School of Electronic and Optical Engineering, Nanjing University of Science and Technology, \\ Xiao Lingwei Road 200, Nanjing, Jiangsu, 210094 China \\ `Jet Propulsion Labs, California Institute of Tech., Pasadena, CA \\ ${ }^{d}$ College of Chemistry and Molecular Sciences, Wuhan University, Wuhan, China \\ ${ }^{e}$ Department of Chemistry and Biochemistry, University of Oregon, Eugene, Oregon 97403- \\ 1253, United States, \\ fDepartment of Chemistry, Boston College, Chestnut Hill, Massachusetts 02467-3860, United \\ States \\ gkukolich@u.arizona.edu
}




\section{(Abstract)}

1,2-BN cyclohexene has been produced from 1,2-BN cyclohexane through the loss of $\mathrm{H}_{2}$ and characterized and identified using a pulsed-beam Fourier-transform microwave spectrometer. Microwave spectra were measured in the frequency range of $5.5-12.5 \mathrm{GHz}$, providing accurate rotational constants and quadrupole coupling strengths. Results of high level calculations allowed clear assignment ofthe spectra to1,2-BN Cyclohexene. Heating the initial compound, 1,2-BN Cyclohexane, to $60^{\circ} \mathrm{C}$ in a $1 \mathrm{~atm}$. neon stream results in the loss of $\mathrm{H}_{2}$ and conversion to 1,2-BN Cyclohexene and this appears to be the first characterization of this compound as the 1,2-BN Cyclohexene monomer.

\section{Introduction}

Amine-boranes have received considerable attention in the past two decades because of their potential application as chemical hydrogen storage materials. ${ }^{1}$ The parental compound of this family of materials, ammonia borane $\left(\mathrm{NH}_{3} \cdot \mathrm{BH}_{3}\right),{ }^{2}$ is an air-stable solid with a hydrogen content of $19.6 \mathrm{wt} \%$, and its thermal ${ }^{3}$ and catalytic ${ }^{4}$ decomposition to desorb $\mathrm{H}_{2}$ has been intensively studied. The Liu lab has been engaged in the development of chemical hydrogen storage materialsthat in addition to boron and nitrogen also contain the element carbon (CBN materials). These $\mathrm{CBN}$ compounds have been reported to exhibit useful features such as improved thermal stability, ${ }^{5}$ room-temperature liquid-phase behavior, ${ }^{6}$ can be readily regenerated by adding hydrogen, ${ }^{6,7}$ and thermodynamics conducive to 
improved efficiency. ${ }^{8} \mathrm{BN}$ Cyclohexane is a cyclic $\mathrm{CBN}$ material with a single $\mathrm{BN}$ substitution in the cyclohexane ring. ${ }^{9}$ It decomposes thermally to cleanly generate the trimerT with concomitant release of 6 equiv. of $\mathrm{H}_{2}$ per trimer (Scheme 1). A presumed intermediate under the thermal decomposition conditions is the cyclic aminoboraneBN Cyclohexene (Scheme 1). BN Cyclohexene has remained elusive without previous characterization because as a simple non-sterically encumbered aminoborane,${ }^{10}$ it is prone to dimerization or oligomerization in solution, consistent with the formation of the trimerT as the ultimate decomposition product. In this work, we describe the gas phase microwave spectroscopy characterization of BN Cyclohexene, which is produced from BN cyclohexane under microwave spectroscopy measurement conditions (i.e., heating sample in a Ne gas stream prior to insertion into the microwave cavity) This process is illustrated in the lower portion of Scheme 1. (this work - microwave spectroscopy)..

Scheme 1. BN Cyclohexane and BN Cyclohexene

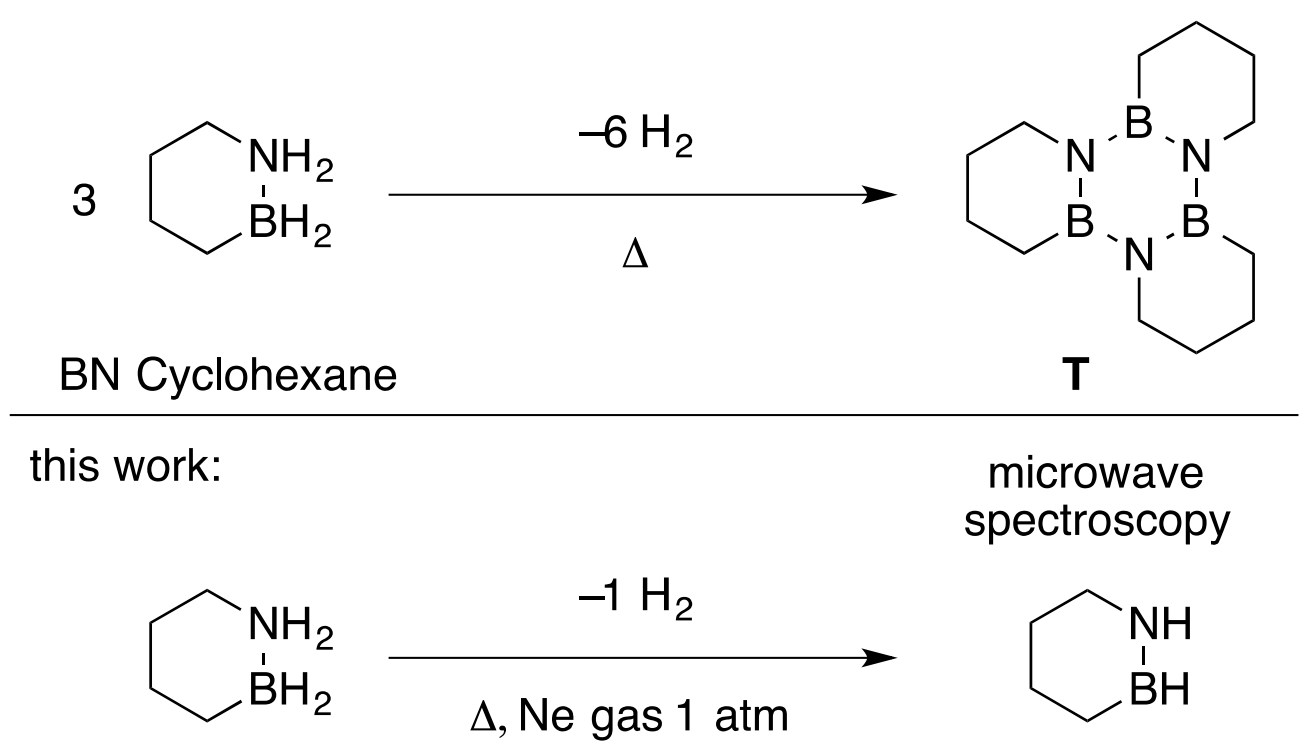

BN Cyclohexane

BN Cyclohexene

Gas phase microwave spectroscopy provides an accurate method to accurately determine molecular structures to positively identify compounds and to probe details of the electronic charge 
distribution. The nitrogen and boronquadrupole coupling strengths provide details of the local charge distribution at these sites. Previously publishedmicrowave spectroscopy measurementson the aromatic 1,2-dihydro-azaborine ${ }^{11}$ (with a single BN substitution into benzene) provided rotational constants and quadrupole coupling strengths for three isotopologues, $\mathrm{H}_{6} \mathrm{C}_{4}{ }^{11} \mathrm{~B}^{14} \mathrm{~N}, \mathrm{H}_{6} \mathrm{C}_{4}{ }^{10} \mathrm{~B}^{14} \mathrm{~N}$, and $\mathrm{H}_{5} \mathrm{DC}_{4}{ }^{11} \mathrm{~B}^{14} \mathrm{~N}$. The data were used to accurately determine coordinates for the substituted atoms and provide sufficient data to determine most of the important structural parameters for this molecule. The quadrupole coupling strengths provided important and useful probes of chemical bonding and the electronic structure of a molecule. ${ }^{12}$ Interpretation of the nuclear quadupole coupling strengthsusing the extended Townes-Daily analysis ${ }^{13}$ provided additional information regarding the aromaticity. The nitrogeneQqcomponent parallel to the c-axis for is consistent with other nitrogen-containing aromatic molecules. Microwave measurements on $\mathrm{N}-\mathrm{Et}-1,2$-azaborine were also reported. ${ }^{14}$ Other compounds studied using microwave spectroscopy which involve $\mathrm{B}-\mathrm{N}$ bonding areAziridine-Borane $\left(\mathrm{C}_{2} \mathrm{H}_{5} \mathrm{~N}\right.$ $\left.\mathrm{BH}_{3}\right){ }^{15} \mathrm{H}_{3} \mathrm{~N}-\mathrm{BF}_{3},{ }^{16}$ ammonia-borane $\left(\mathrm{H}_{3} \mathrm{~N}-\mathrm{BH}_{3}\right),{ }^{17}$ aminoborane $\left(\mathrm{H}_{2} \mathrm{~N}-\mathrm{BH}_{2}\right),{ }^{18}$ aminodifluoroborane $\left(\mathrm{NH}_{2}-\right.$ $\left.\mathrm{BF}_{2}\right),{ }^{19}$ and diaminoborane $\left(\mathrm{HB}\left(\mathrm{NH}_{2}\right)_{2}\right){ }^{20}$

For the present measurements we started with the compound synthesized and characterized by Liu, et al. ${ }^{9}$ as 1,2-BN Cyclohexane $\left(\mathrm{C}_{4} \mathrm{H}_{12} \mathrm{BN}\right)$. It was verified with NMR data that two $\mathrm{H}$ atoms were bound to B for that starting compound. After comparing the calculatedrotational constants and quadrupole coupling parameters for 1,2-BN Cyclohexaneand 1,2-BN Cyclohexene $\left(\mathrm{C}_{4} \mathrm{H}_{10} \mathrm{BN}\right)$ with values from the experimental microwave spectrum, it is clear that the compound we observed in the vapor phase is 1,2-BN Cyclohexene. Heating the 1,2-BN Cyclohexane sample $(60 \mathrm{C})$ to obtain sufficient vapor pressure apparently caused the loss of $\mathrm{H}_{2}$, yielding the 1,2-BN Cyclohexene. It does not appear that 1,2-BN Cyclohexene has been previously characterized. This new work presents the opportunity to compare the rotational constants andquadrupole coupling strengths for 1,2-BN Cyclohexene, a non-planar molecule with the aromatic, planar 1,2-dihydro-1,2-azaborine.The ${ }^{11} \mathrm{~B}$ isotopologue inertial defect is $\Delta_{0}=-20.78 \mathrm{amu} \cdot \AA^{2}$ clearly indicating a nonplanar structure, in contrast to 
the inertial defect $\Delta_{0}=0.02 \mathrm{amu} \cdot \AA^{2}$ for 1, 2-dihydro-1,2-azaborine. The synthesis, structure and reactivity of 1,2-BN Cyclohexane were described previously by the Liu group. ${ }^{9}$

\section{COMPUTATIONAL METHODS AND RESULTS}

The results of ab-initio calculations on small molecules, such as azaborine or 1,2-BN cyclohexane, are sufficiently accurate to predict structures and rotational constants which are very close to the experimental values. This saves considerable time in searching for transitions using a Flygare-Balle type high resolution spectrometer. The present electronic structure calculations were performed using the Gaussian 09 program suite. ${ }^{21}$ The calculations for the ground state structures and electronic properties were done using Moller-Plesset second-order perturbation theory (MP2) and Density Functional Theory (DFT) with B3LYP and B97D functionals. Augmented triple-zeta and quadruple-zeta correlation consistent basis sets were used(aug-cc-pVTZ and aug-cc-pVQZ). The converged, energy minimum structures obtained using B3LYP/aug-cc-pVTZare shown in Fig. 1 [a)-1,2BN Cyclohexane, b)-1,2-BN Cyclohexene] 

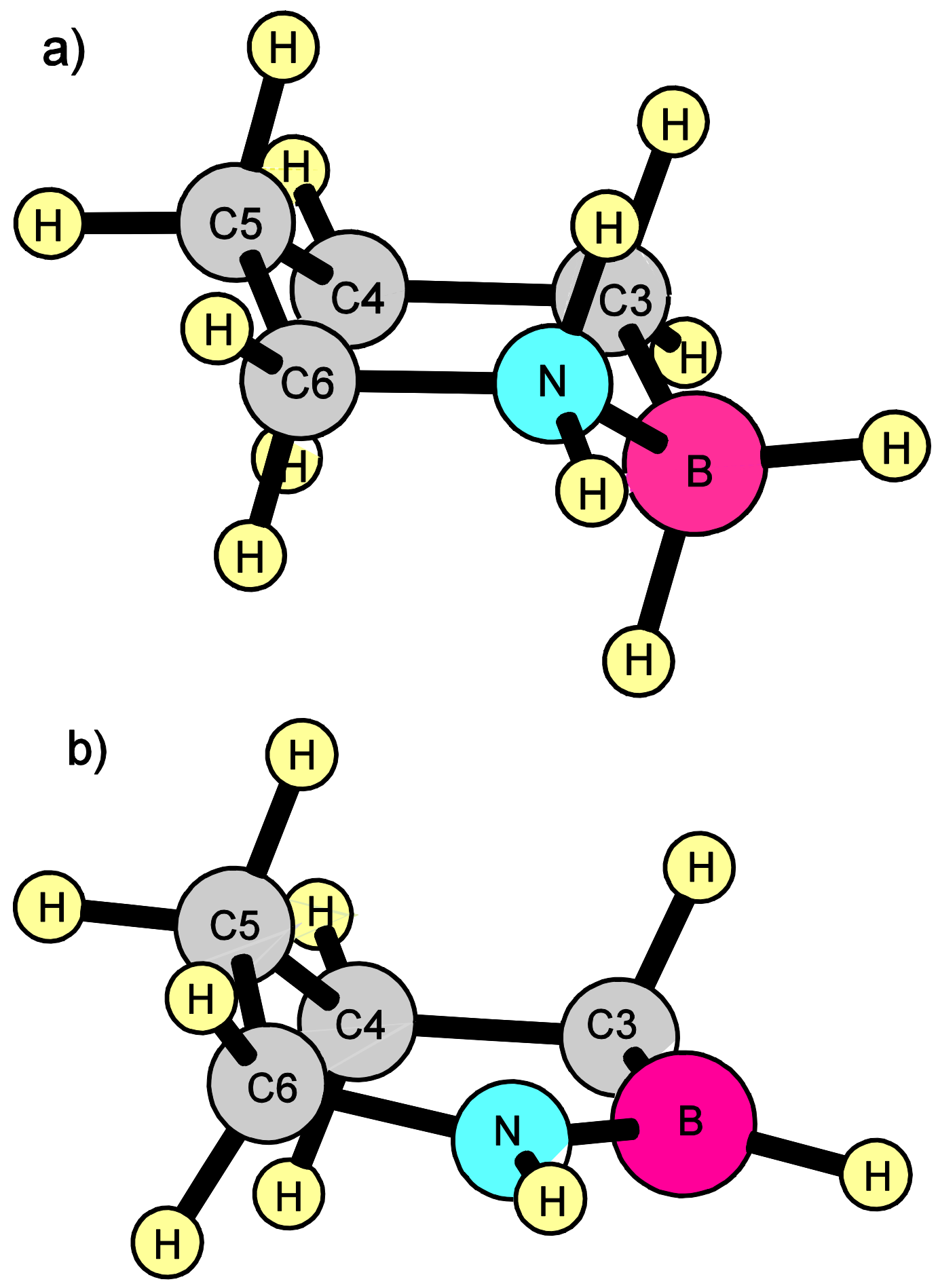

Fig. 1 Calculated structures for a)-1,2-BN Cyclohexane, b)-1,2-BN Cyclohexene obtained using B3LYP, aug-cc-pVTZ basis. The c-axis is perpendicular to the approximate plane of the C-C-C-C-B-N ring and the b-axis passes close to the $\mathrm{B}$ atom. 
We note that 1,2-BN Cyclohexane (a) is in the traditional "chair" conformation found for cyclohexane whereas the C1-C4-B-N-C3 atoms are nearly in a plane for 1,2-BN cyclohexene (b) in a "half-chair" conformation.

a) Rotational Constants and Nuclear Quadrupole Coupling Strengths The calculated rotational constants and quadrupole coupling strengths for 1,2-BN cyclohexane and1,2-BN cyclohexeneare shown in Table 1., along with the experimental results for rotational constants and quadrupole coupling strengths for 1,2-BN cyclohexene. We can see that the B3LYP/aug-cc-pVTZ calculated rotational constants for 1,2-BN cyclohexeneare in excellent agreement with experimental values. The B3LYP/aug-cc-pVQZ and MP2 and B97D calculated rotational constants were not as close to experimental values. Most values calculated for quadrupole coupling parameters were larger than experimental values. The calculated eQq values for ${ }^{11} \mathrm{~B}$ using MP2/aug-cc-pVTZ are in good agreementwith experiment, but other calculated eQq values are much poorer.Calculated rotational constants and quadrupole coupling strengths for 1,2-BN cyclohexane do not agree well at all with the experimental values, essentially ruling out that structure for our gas-phase experiments. The calculated structural parameters for 1,2-BN Cyclohexene and1,2-BN Cyclohexaneare given in Tables 2 and 3. The calculated B-N bond length for $1,2-B N$ cyclohexene is $1.40 \AA$, for $1,2-B N$ cyclohexane, $1.66 \AA$, and for the aromatic 1,2-dihydro-1,2-azaborine, $1.45 \AA$. Table 3 shows the calculated and experimental ${ }^{9}$ structural parameters for 1,2-BN Cyclohexane $\left(\mathrm{BNC}_{4} \mathrm{H}_{12}\right)$. A comparison of the calculated quadrupole coupling strengths $\left(X_{\mathrm{ii}}\right)$ for $1,2-{ }^{11} \mathrm{BN}$ Cyclohexane, $1,2-{ }^{11} \mathrm{BN}$ Cyclohexene and ${ }^{11} \mathrm{~B}$ azaborine is given in Table 4.

b) Calculated Dipole Moments The dipole moment components along the principal inertial axes for BN-cyclohexane, BN-cyclohexene and azaborine were calculated using Gaussian - G09 with MP2 and B3LYP using augmented triple zeta basis sets. Results were very similar for both methods and are given in Table 5. Interestingly, the overall dipole moments for all three of these B-N substituted molecules are in directions nearly parallel to the B-N bonds, but in a direction opposite to the (+)B-N(-) bond dipole direction. For these molecules, the charges on the $\mathrm{B}$ and $\mathrm{N}$ atoms polarize the adjacent 
bonds to carbon making C6 positive (+) and C3 negative (-). Since C6 and C3 are separated by a larger distance than $\mathrm{B}$ and $\mathrm{N}$, the charges on $\mathrm{C} 6$ and $\mathrm{C} 3$ dominate the overall dipole moments for the molecules. Here we are using the Physics convention for the direction dipole moments $(-\rightarrow+)$, which is consistent with dipoles tending to align with the electric field $(\varepsilon)$ with energy $E=-\vec{\mu} \bullet \vec{E}$. The calculated dipole components for BN-cyclohexane are substantially larger than for BN-cyclohexene.If $\mathrm{N}-\mathrm{H}$ bonds are more ionic than $\mathrm{B}-\mathrm{H}$ bonds, adding one additional $\mathrm{H}$ atom to both $\mathrm{N}$ and $\mathrm{B}$ could donate more negative charge to $\mathrm{N}$, increasing the polarization of the $\mathrm{B}-\mathrm{N}$ bond.

\section{EXPERIMENT}

The sample of the precursor compound, 1,2-BN Cyclohexanewas synthesized in the Liu laboratory. The detailed synthesis of this molecule has been published previously. ${ }^{9}$ The solid sample was placed in a glass cell attached to the General Valve Series 9 pulse valve and the sample cell and valve heated to 50 to $90^{\circ} \mathrm{C}$ to obtain sufficient vapor pressure in the 1 atmneon gas stream. The gasinlet of the sample cell was connected to the neon gas delivery system.

We used two pulsed molecular beam Fourier transform microwave spectrometers to measure rotational spectra for 1,2-BN Cyclohexene. The spectrometers are similar to the Flygare-Balle microwave spectrometer system, but employ homodyne (zero-IF) detection method, the details of which can be found in previous papers. ${ }^{22,23}$. The rotational spectrum of 1,2-BN Cyclohexenewas measured in the $5.5-12.5 \mathrm{GHz}$ microwave frequency range. Based on initial theoretical predictions for $1,2-{ }^{11} \mathrm{BN}$ Cyclohexene, several a-type and $b$-type rotation transitions were predicted to lie within the 5$12 \mathrm{GHz}$ frequency range. In performing typical measurements, molecular beams containing 1,2-BN Cyclohexene were pulsed into the high vacuum $\left(10^{-6}\right.$ torr) microwave cavity at the rate of about $2 \mathrm{~Hz}$, using a $0.8 \mathrm{~mm}$ dia. nozzle (General valve, series 9). Neon was used as a carrier gas and to provide supersonic (adiabatic) cooling of the molecule. The neon backing pressure inside the cell was constantly maintained throughout the experiments at about $1 \mathrm{~atm}$. After a short delay (about $1 \mathrm{~ms}$.) to 
allow the supersonically cooled 1,2-BN Cyclohexene - neon mixture to reach the center region of the microwave cavity, they were radiated with short (about $1 \mu \mathrm{s}), \pi / 2$ microwave pulses. The microwave emission signals (molecular free induction decay) were detected in the time domain and sampled at 10 $\mathrm{MHz}$ via an 8-bit transient recorder. The digitized time domain signals were fast Fourier transformed to obtain the frequency spectrum. A typical spectral line resolution, measured at the full width halfmaximum, is about $10-15 \mathrm{kHz}$ for a strong, unperturbed rotational line using our spectrometers with the homodyne detection. Many transitions for both the less abundant boron $\left({ }^{10} \mathrm{~B}\right)$ isotopologue and the "normal" boron $\left({ }^{11} \mathrm{~B}\right)$ isotopologues were measured and the frequencies are listed in the Supplementary Materials section, Tables S1 and S2. An example of the hyperfine structure observed for the $0_{00} \rightarrow 1_{11}$ for $1,2-{ }^{11} \mathrm{BN}$ Cyclohexene is shown in Figure 2.

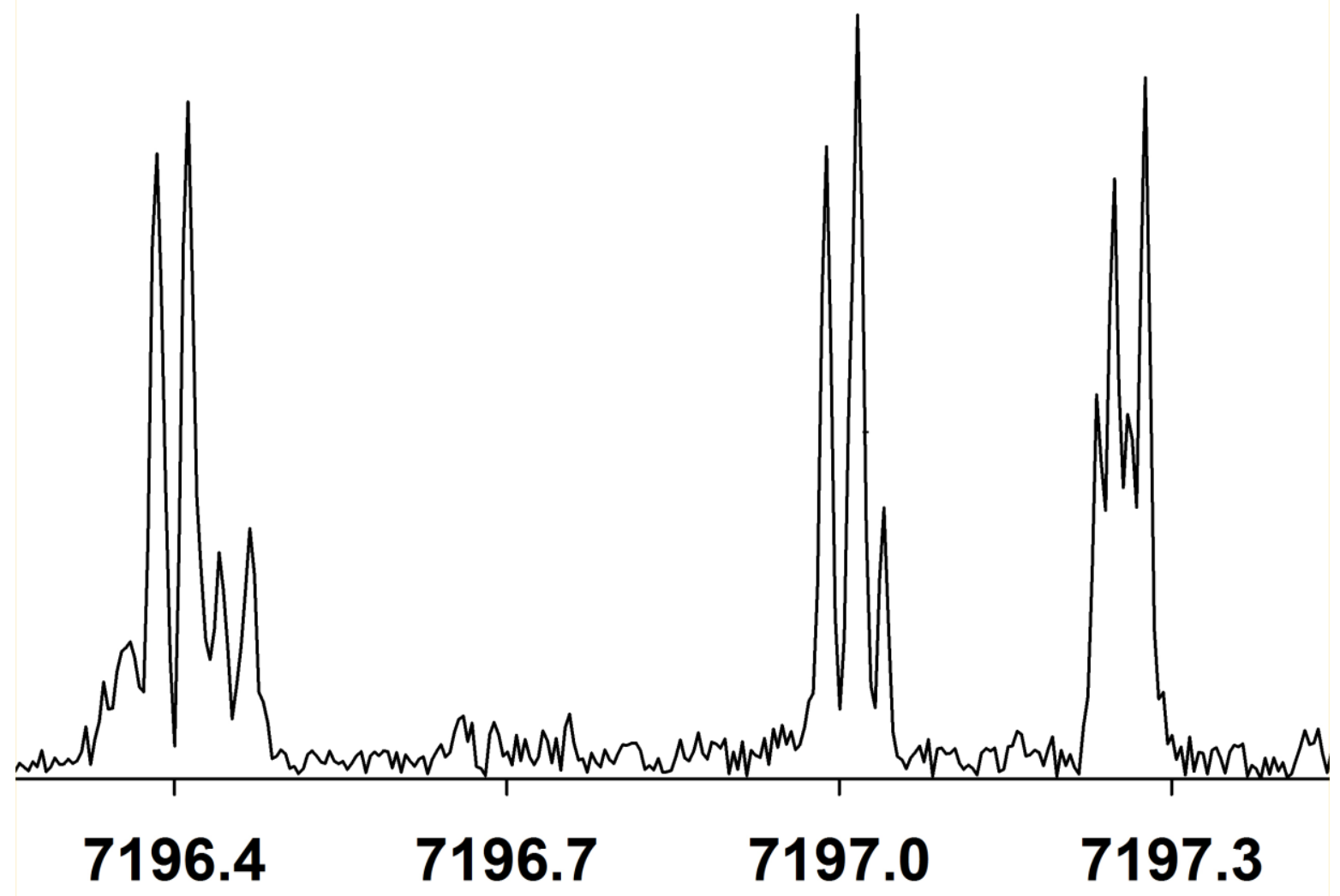

Figure 2. The $0_{00} \rightarrow 1_{11}$ transitions for $1,2-{ }^{11} \mathrm{BN}$ Cyclohexene showing the quadrupole hyperfine structure arising from ${ }^{11} \mathrm{~B}$ and ${ }^{14} \mathrm{~N}$ interactions. 
Initial scans were made from 7200 to $6700 \mathrm{MHz}$ covering the $\mathrm{J}^{\prime \prime}=0 \rightarrow \mathrm{J}^{\prime}=1$ a-dipole and b-dipole transitions using the low resolution transverse beam spectrometer. ${ }^{24} T$ The complex hyperfine structure patterns due to the quadrupole coupling interactions of ${ }^{14} \mathrm{~N}(\mathrm{l}=1)$ and ${ }^{10} \mathrm{~B}(\mathrm{I}=3)$ or ${ }^{11} \mathrm{~B}(\mathrm{I}=3 / 2)$ with the rotational angular momentum were observed at $7196\left({ }^{11} \mathrm{~B}\right.$ see Fig. 2) and $6854 \mathrm{MHz}\left(0_{00} \rightarrow 1_{01}\right)$.Next, the partially resolved spectrum for the $\mathrm{J}^{\prime \prime}=1 \rightarrow \mathrm{J}^{\prime}=2 \mathrm{a}$-dipole transitions at $12.1 \mathrm{GHz}\left(1_{01} \rightarrow 2_{02}\right)$ and $\mathrm{b}$ dipole transitions at $11.8 \mathrm{GHz}\left(1_{11} \rightarrow 2_{02}\right)$ transitions were measured. Once the rotational constants were obtained by fitting these transitions, scans using the co-axial beam spectrometer ${ }^{23}$ were performed to take advantage of the superior resolution and this enabled assignment of the hyperfine transitions. The majority of the observed lines were a-type transitions. Surprisingly, the observed $b$ type transitions were noticeably weaker than the a-type transitions even though theoretical calculations predicted the $b$-type transitions to be as strong as the a-type transitions ( $\sim 1.5$ debye). A search was made for possible transitions for ${ }^{11} \mathrm{BN}$-cyclohexane usingcalculated rotational constants given in Table 1. Some additional transitions have been observed but no definitive assignments for the ${ }^{11} \mathrm{BN}$ cyclohexane have been made.

\section{SPECTRAL ANALYSIS AND RESULTS}

Despite the spectral complexity, the assignments of the hyperfine splittings were managed by first carefully studying the resolved hyperfine components in the $\mathrm{J}=0_{00} \rightarrow 1_{11}$ line then the $\mathrm{J}=1_{11} \rightarrow 2_{12}$ lines. The analyses of the observed hyperfine structure splittings were accomplished using the SPFIT and SPCAT spectral analysis programs described by Pickett. ${ }^{25}$ To fit the spectrum, we used Watson's A-reduction ${ }^{26}$ Hamiltonian for a distortable rotor coupled with the nuclear quadrupole hyperfine interaction terms. The nuclear spin angular momentadue to Boron and Nitrogen $\left({ }^{11} \mathrm{~B}: \mathrm{I}=3 / 2\right.$ and ${ }^{14} \mathrm{~N}: \mathrm{I}=$ 1) are coupled as $\mathbf{F}_{\mathbf{1}}=\mathbf{J}+\mathbf{I}\left({ }^{11} \mathbf{B}\right)$ and $\mathbf{F}=\mathbf{F}_{\mathbf{1}}+\mathbf{I}\left({ }^{14} \mathbf{N}\right)$, where $\mathbf{F}$ is the total angular momentum. The rotation and hyperfine Hamiltonians are shown below. 
$H(\text { Watson's A-reduced oblate III representation })^{26}$

$$
\begin{aligned}
H= & \frac{A+B}{2} \hat{J}^{2}+\left(C-\frac{A+B}{2}\right) \hat{J}_{z}^{2}+\frac{A-B}{4}\left(\hat{J}_{+}^{2}+\hat{J}_{-}^{2}\right)-\Delta_{J} \hat{J}^{4} \\
& -\Delta_{J K} \hat{J}^{2} \hat{J}_{z}^{2}-\Delta_{K} \hat{J}_{z}^{4}-\frac{1}{2}\left\{\delta_{J} \hat{J}^{2}+\delta_{K} \hat{J}_{z}^{2}, \hat{J}_{+}^{2}+\hat{J}_{-}^{2}\right\}
\end{aligned}
$$

\section{$H($ Hyperfine)}

$$
\begin{aligned}
& \left\langle K^{\prime} J^{\prime} I F M_{F}\left|H_{\mathrm{Q}}\right| K J I F M_{F}\right\rangle=(-1)^{J+I+F}\left[2\left(\begin{array}{rrr}
I & 2 & I \\
I & 0 & -I
\end{array}\right)\right]^{-1} \\
& \times\left\{\begin{array}{lll}
F & I & J^{\prime} \\
2 & J & I
\end{array}\right\} \sqrt{(2 J+1)\left(2 J^{\prime}+1\right)} \frac{1}{2} \\
& \times\left[(-1)^{J-K}\left(\begin{array}{rrr}
J & 2 & J^{\prime} \\
K & 0 & -K^{\prime}
\end{array}\right)\right. \\
& \times \chi_{a a} \mp(-1)^{J-K \mp 1}\left(\begin{array}{rrc}
J & 2 & J^{\prime} \\
K & \pm 1 & -K^{\prime}
\end{array}\right) \\
& \times \sqrt{\frac{2}{3}} \chi_{a b}+(-1)^{J-K \mp 2} \\
& \left.\times\left(\begin{array}{rrr}
J & 2 & J^{\prime} \\
K & \pm 2 & -K^{\prime}
\end{array}\right) \frac{1}{\sqrt{6}}\left(\chi_{b b}-\chi_{c c}\right)\right],
\end{aligned}
$$

A total of 146 hyperfine components (including both isotopologues) were analyzed and fit using the above Hamiltonian. In this analysis, only the $\Delta_{\mathrm{J}}$ and $\Delta_{\mathrm{J}}$ centrifugal distortion constants were required to obtain a good fit, indicating a fairly rigid structure. The standard deviations of the fit are good to within the experimental uncertainties, and only eight parameters were used to fit these lines. Table 1 provides a summary of our resulting fit parameters. Distortion constants $\Delta_{\mathrm{J}}$ and $\Delta_{\mathrm{JK}}$ for the ${ }^{10} \mathrm{~B}$ fit were fixed to values obtained for ${ }^{11} \mathrm{~B}$. A list of the observed frequencies and fit residuals are given in Tables $\mathrm{S} 1$ and S2 (These tables are published as Supplementary Materials). The "best fit" molecular parameters are listed in Table 1. 


\section{CONCLUSIONS}

New data obtained from the gas phase microwave measurements and subsequent analysis provided by the fully resolved hyperfine spectrum shows that heating 1,2 BN cyclohexane in a 1 atm neon stream results in the loss of $\mathrm{H}_{2}$ and conversion to $1,2 \mathrm{BN}$ cyclohexene. The complex spectra were analysed to obtain rotational constants and $B$ and $N$ quadrupole coupling parameters for $1,2^{10} \mathrm{BN}$ cyclohexene and 1,2 ${ }^{11} \mathrm{BN}$ cyclohexene. The B3LYP/aug-cc-pVTZ calculated rotational constants for 1,2-BN cyclohexene are in excellent agreement with experimental values whereas similar calculated rotational constants for 1,2-BN cyclohexanedo not agree with the experimental values. Calculated 
quadrupole coupling strengths for 1,2-BN cyclohexane also do not agree well at all with the experimental values, essentially ruling out that structure for our gas-phase experimental results.

We note from Table 1. that the nitrogen $\chi_{\mathrm{ij}}$ parameters for ${ }^{10} \mathrm{~B}$ and ${ }^{11} \mathrm{~B}$ isotopolgues agree very well, adding confidence to the analysis. Rotation of the $a$ and $b$ principal axes on substitution of ${ }^{10} \mathrm{~B}$ for ${ }^{11} \mathrm{~B}$ is too small to be significant. The calculated $\mathrm{B}-\mathrm{N}$ bond length for $1,2-\mathrm{BN}$ cyclohexene is $1.40 \AA$, for 1,2-BN cyclohexane, $1.66 \AA$, and for the aromatic 1,2-dihydro-1,2-azaborine, $1.45 \AA$.

\section{ACKNOWLEDGEMENTS}

This material is based upon work supported by the National Science Foundation under Grant No. CHE-1057796 at the University of Arizona. Financial support has been provided by the U.S. Department of Energy (DE-EE-0005658). S.-Y.Liu thanks the Camille Dreyfus Teacher-Scholar Awards Program for a Teacher-Scholar award.

We thankSpencer J. Carey for help in collecting some of the preliminary data for this compound and Kexin Li for NMR measurements. We thank Mike Barfield for helpful discussions on this work. 
Table 1. Calculated and experimental molecular Parameters for $1,2-{ }^{11} \mathrm{BN}$ Cyclohexane, $1,2-{ }^{10} \mathrm{BN}$ Cyclohexene and 1,2-

${ }^{11} \mathrm{BN}$ Cyclohexene in MHz. Basis sets for calculations - B3LYP/aug-cc-pVTZ, MP2/aug-cc-pVTZ and MP2/aug-cc-pVQZ.

\begin{tabular}{|c|c|c|c|c|c|c|c|}
\hline \multirow[t]{2}{*}{ Parameter } & \multirow{2}{*}{$\begin{array}{c}\begin{array}{c}1,2^{-11} \mathrm{BN} \\
\text { Cyclohexane }\end{array} \\
\text { B3LYP(TZ) }\end{array}$} & \multicolumn{2}{|c|}{$1,2-^{10} \mathrm{BN}$ Cyclohexene } & \multicolumn{4}{|c|}{$1,2-^{11} \mathrm{BN}$ Cyclohexene } \\
\hline & & Experiment & B3LYP(TZ) & Experiment & B3LYP(TZ) & MP2(TZ) & MP2(QZ) \\
\hline A & 4253.09 & $4802.0662(17)$ & 4801.95 & $4702.0578(17)$ & 4701.56 & 4737.93 & 4754.95 \\
\hline B & 4054.51 & $4360.3237(18)$ & 4365.95 & $4360.3340(10)$ & 4365.76 & 4388.67 & 4404.60 \\
\hline C & 2368.44 & $2522.1449(7)$ & 2514.32 & $2494.4070(10)$ & 2486.58 & 2514.02 & 2523.18 \\
\hline $1.5 X_{\mathrm{aa}}(\mathrm{B})$ & 0.905 & $-5.6218(92)$ & -6.207 & $-2.6984(78)$ & -2.980 & -2.698 & -2.804 \\
\hline $0.25\left(X_{\mathrm{bb}}-X_{\mathrm{cc}}\right)(\mathrm{B})$ & 0.266 & $-2.8031(37)$ & -3.123 & $-1.3570(29)$ & -1.150 & -1.438 & -1.469 \\
\hline $1.5 X_{\mathrm{Xa}}(\mathrm{N})$ & -1.463 & $0.5533(61)$ & 0.625 & $0.5530(62)$ & 0.629 & 0.361 & 0.404 \\
\hline $0.25\left(X_{\mathrm{bb}}-X_{\mathrm{cc}}\right)(\mathrm{N})$ & -0.168 & $1.1600(21)$ & 1.227 & $1.1569(15)$ & 1.227 & 1.115 & 1.136 \\
\hline$\Delta_{\lrcorner}(\mathrm{kHz})$ & & & & $0.15(14)$ & & & \\
\hline$\Delta_{\mathrm{JK}}(\mathrm{kHz})$ & & & & $-1.59(40)$ & & & \\
\hline$\Delta_{0}\left(\mathrm{amu} \AA^{2}\right)$ & & -20.77 & & -20.78 amu $\AA^{2}$ & & & \\
\hline $\mathrm{N}$ (lines) & & 63 & & 83 & & & \\
\hline rms error & & $0.0039 \mathrm{MHz}$ & & $0.0061 \mathrm{MHz}$ & & & \\
\hline
\end{tabular}


Table 2. Bond lengths and interbond angles for $B N$ cyclohexene $\left(\mathrm{BNC}_{4} \mathrm{H}_{10}\right)$. Calculated with B3LYP triple-zeta basis.

\begin{tabular}{|c|c|c|c|}
\hline Bond & Bond Length $(\AA)$ & & Angles (degrees) \\
\hline B-N & 1.40 & $\angle \mathrm{B}-\mathrm{N}-\mathrm{C} 6$ & 125 \\
\hline $\mathrm{N}-\mathrm{C} 6$ & 1.47 & $\angle \mathrm{N}-\mathrm{C} 6-\mathrm{C} 5$ & 111 \\
\hline C6-C5 & 1.53 & $\angle \mathrm{C} 6-\mathrm{C} 5-\mathrm{C} 4$ & 112 \\
\hline C5-C4 & 1.53 & $\angle \mathrm{C} 5-\mathrm{C} 4-\mathrm{C} 3$ & 111 \\
\hline C4-C3 & 1.54 & $\angle \mathrm{C} 4-\mathrm{C} 3-\mathrm{B}$ & 113 \\
\hline C3-B & 1.58 & $\angle \mathrm{C} 3-\mathrm{B}-\mathrm{N}$ & 119 \\
\hline
\end{tabular}

Table 3. Bond lengths and interbond angles for $\mathrm{BN}$ cyclohexane $\left(\mathrm{BNC}_{4} \mathrm{H}_{12}\right)$. Calculated with B3LYP triple-zeta basis. X-ray data from ref 9.

\begin{tabular}{|c|c|c|c|c|c|}
\hline Bond & $\begin{array}{c}\text { Bond Length } \\
\text { Calculated } \\
(\AA)\end{array}$ & $\begin{array}{c}\text { Bond } \\
\text { Length } \\
\text { X-RAY }(\AA)\end{array}$ & $\begin{array}{c}\text { Angles } \\
\text { Calculated } \\
\text { (degrees) }\end{array}$ & $\begin{array}{c}\text { Angles } \\
\text { X-Ray } \\
\text { (degrees) }\end{array}$ \\
\hline B-N & 1.66 & $1.614(1)$ & $\angle B-N-C 6$ & 113 & $113.13(6)$ \\
\hline N-C6 & 1.49 & $1.489(1)$ & $\angle$ N-C6-C5 & 111 & $110.58(7)$ \\
\hline C6-C5 & 1.53 & $1.521(1)$ & $\angle$ C6-C5-C4 & 113 & $112.66(7)$ \\
\hline C5-C4 & 1.53 & $1.527(1)$ & $\angle C 5-C 4-C 3$ & 112 & $110.90(7)$ \\
\hline C4-C3 & 1.54 & $1.529(1)$ & $\angle$ C4-C3-B & 113 & $111.86(7)$ \\
\hline C3-B & 1.62 & $1.609(1)$ & $\angle C 3-B-N$ & 106 & $107.47(7)$ \\
\hline
\end{tabular}


Table 4. Comparison of quadrupole coupling parameters $\left(X_{\text {ii }}\right)$ for $1,2-{ }^{11} \mathrm{BN}$ Cyclohexane, $1,2-{ }^{11} \mathrm{BN}$ Cyclohexene and ${ }^{11} \mathrm{~B}$ azaborine in $\mathrm{MHz}$.

\begin{tabular}{|c|c|c|c|}
\hline Parameter & $\begin{array}{c}1,2^{-11} \mathrm{BN} \\
\text { Cyclohexane }\end{array}$ & $\begin{array}{c}1,2-{ }^{11} \mathrm{BN} \\
\text { Cyclohexene }\end{array}$ & ${ }^{11}$ B-azaborine \\
\hline & B3LYP(TZ) & Experiment & Experiment \\
\hline$X_{\text {aa }}(\mathrm{B})$ & 0.603 & $-1.799(5)$ & $-1.71(1)$ \\
\hline$X_{\mathrm{bb}}(\mathrm{B})$ & 0.231 & $-1.815(3)$ & $-1.33(2)$ \\
\hline$X_{\mathrm{cc}}(\mathrm{B})$ & -0.834 & $3.613(5)$ & $3.03(2)$ \\
\hline $1.5 X_{\mathrm{aa}}(\mathrm{B})$ & 0.905 & $-2.6984(78)$ & $-2.56(1)$ \\
\hline $0.25\left(X_{\mathrm{bb}}-X_{\mathrm{cc}}\right)(\mathrm{B})$ & 0.266 & $-1.3570(29)$ & $-1.09(2)$ \\
\hline $1.5 X_{\text {aa }}(\mathrm{N})$ & -1.463 & $0.5530(62)$ & $0.68(1)$ \\
\hline $0.25\left(X_{b b}-X_{c c}\right)(N)$ & -0.168 & $1.1569(15)$ & $0.24(2)$ \\
\hline$X_{\mathrm{aa}}(\mathrm{N})$ & -0.975 & $0.369(4)$ & $0.46(1)$ \\
\hline$X_{\mathrm{bb}}(\mathrm{N})$ & 0.152 & $2.954(3)$ & $0.78(6)$ \\
\hline$X_{\mathrm{cc}}(\mathrm{N})$ & 0.824 & $-3.322(3)$ & $-1.25(6)$ \\
\hline
\end{tabular}


Table 5.Calculateddipole moment components along the principal inertial axes for BNcyclohexane, BN-cyclohexene and azaborine using Gaussian - G09 with MP2 and B3LYP

\begin{tabular}{|c|c|c|c|c|c|c|}
\hline $\begin{array}{c}\text { Dipole } \\
\text { moment }\end{array}$ & \multicolumn{2}{|c|}{ BN-cyclohexane } & \multicolumn{2}{c|}{ BN-cyclohexene } & \multicolumn{2}{c|}{ Azaborine } \\
\hline$(\mathrm{D})$ & MP2 & B3LYP & MP2 & B3LYP & MP2 & B3LYP \\
\hline$\mu_{\mathrm{a}}$ & 2.998 & 3.119 & 1.107 & 1.062 & 1.410 & 1.510 \\
\hline$\mu_{\mathrm{b}}$ & -3.282 & -3.165 & -1.097 & -1.123 & -1.409 & -1.389 \\
\hline$\mu_{\mathrm{c}}$ & 1.362 & 1.300 & 0.119 & 0.119 & 0.0 & 0.0 \\
\hline$\mu_{\text {TOTAL }}$ & 4.649 & 4.630 & 1.563 & 1.550 & 1.994 & 2.052 \\
\hline
\end{tabular}


For an overview, see: (a)Staubitz, A.; Robertson,A. P. M.; I. Manners, I., Chem Rev 2010, 110, 4079-4124. (b) Huang,Z.; Autrey, T., Energy Environ Sci 2012, 5, 9257-9268.

Heldebrant, D. J.; Karkamkar, A.; J. C. Linehan,J. C.; T. Autrey, T., Energy \&Environmental Science 2008, 1, 156-160.

(a) Bowden, M.;Autrey,S. T.; Brown, I.; Ryan, M., CurrApplPhys2008, 8, 498-500.

(b) Shaw,W. J.;Linehan,J. C.;Szymczak, N. K.;Heldebrant, D. J.;Yonker, C.;Camaioni, D. M.; Baker, R. T.;Autrey, T., AngewChemInt Ed Eng/2008, 47, 7493-7496.

For leading references, see: (a) Douglas, T. M;. Chaplin, A. B.;Weller,A. S., J Am ChemSoc 2008, 130, 14432-14433. (b) Denney,M. C.; Pons, V.;Hebden, T. J.;Heinekey, D. M.;Goldberg, K. I.,J Am ChemSoc 2006, 128, 12048-12049. (c) N. Blaquiere, S. Diallo-Garcia, S. I. Gorelsky, D. A. Black, K. Fagnou, J Am ChemSoc 2008, 130, 14034-14035. (d) M. E. Sloan, A. Staubitz, T. J. Clark, C. A. Russell, G. C. Lloyd-Jones, I. Manners, J Am ChemSoc 2010, 132, 3831-3841. D. W. Himmelberger, C. W. Yoon, M. E. Bluhm, P. J. Carroll, L. G. Sneddon, J Am ChemSoc $\quad$ 2009, 131, 14101-14110.

G. Chen, L. N. Zakharov, M. E. Bowden, A. J. Karkamkar, S. M. Whittemore, E. B. Garner, T. C. Mikulas, D. A. Dixon, T. Autrey, S.-Y. Liu, J. Am. Chem. Soc. 2015, 137, 134-137.

W. Luo, P. G. Campbell, L. N. Zakharov, S.-Y. Liu, J Am ChemSoc2011, 133, 19326-19329. (b) W. Luo, D. Neiner, A. Karkamkar, K. Parab, E. B. Garner, D. A. Dixon, D. Matson, T. Autrey, S.-Y. Liu, Dalton Trans 2013, 42, 611-614.

P. G. Campbell, J. S. A. Ishibashi, L. N. Zakharov, S.-Y. Liu, Aust. J. Chem. 2013, 67, 521-524.

P. G. Campbell, L. N. Zakharov, D. J. Grant, D. A. Dixon, S.-Y. Liu, J. Am. Chem. Soc. 2010, 132, 3289-3291.

W. Luo, L. N. Zakharov, S.-Y. Liu, J Am ChemSoc2011, 133, 13006-13009.

For a leading reference describing the reactivity of aminoboranes, see: E. M. Leitao, N. E. Stubbs, A. P. M. Robertson, H. Helten, R. J. Cox, G. C. Lloyd-Jones, I. Manners, J. Am. Chem. Soc. 2012, 134, 16805-16816.

A. M. Daly, C. Tanjaroon, A. J. V. Marwitz, S.-Y.Liu and S. G. Kukolich, J. Am. Chem. Soc.2010, 132(15), 5501-5506

W. Gordy and R. L. Cook, Microwave Molecular Spectra, Ch14, (John Wiley \& Sons, New York, 1984).

Kang, L.; Sunahori, F.; Minei, A.J.; Clouthier, D. J. and Novick, S.E. J. Chem. 


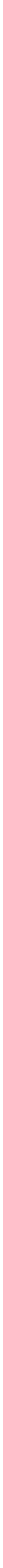

Figure
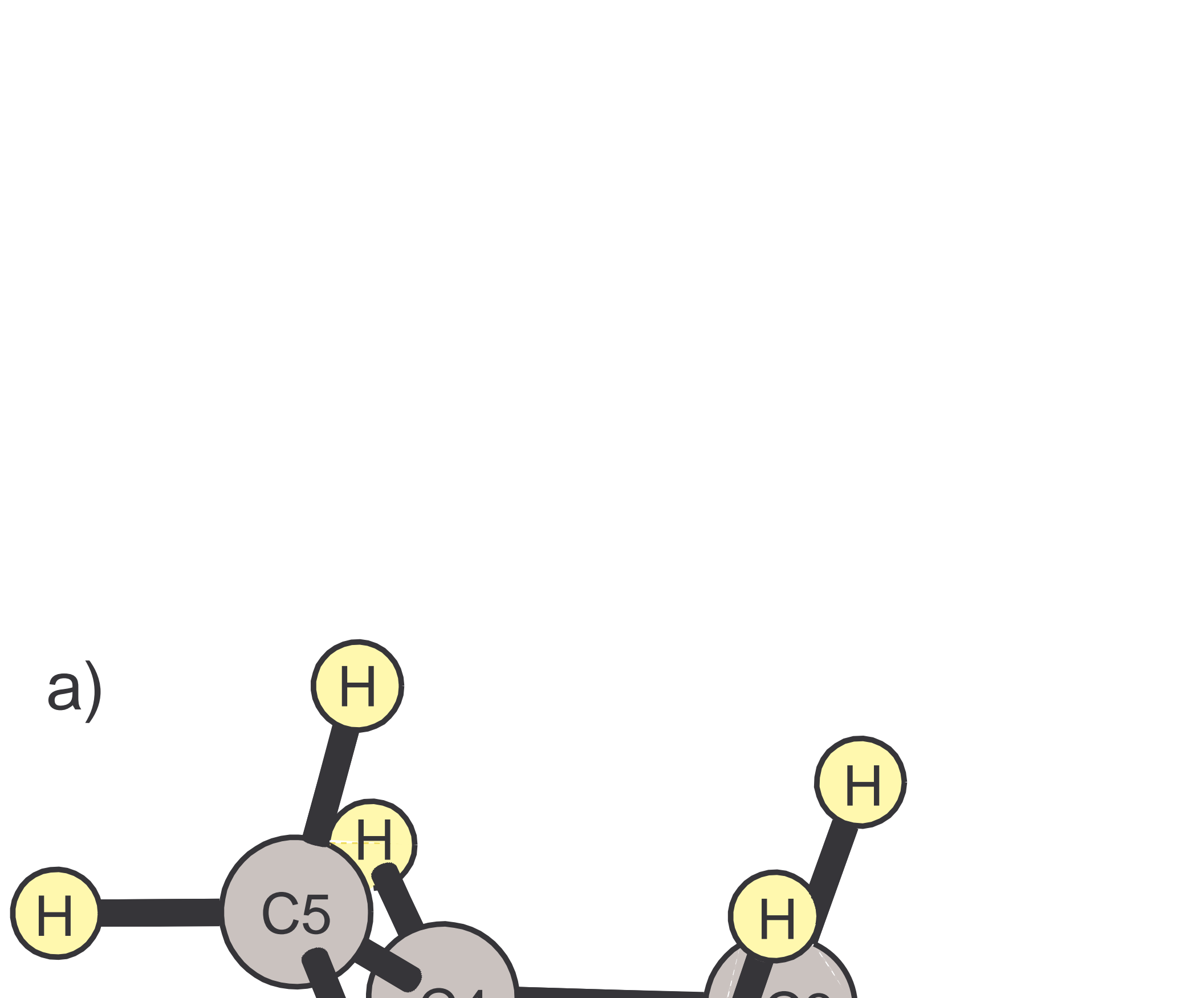

 


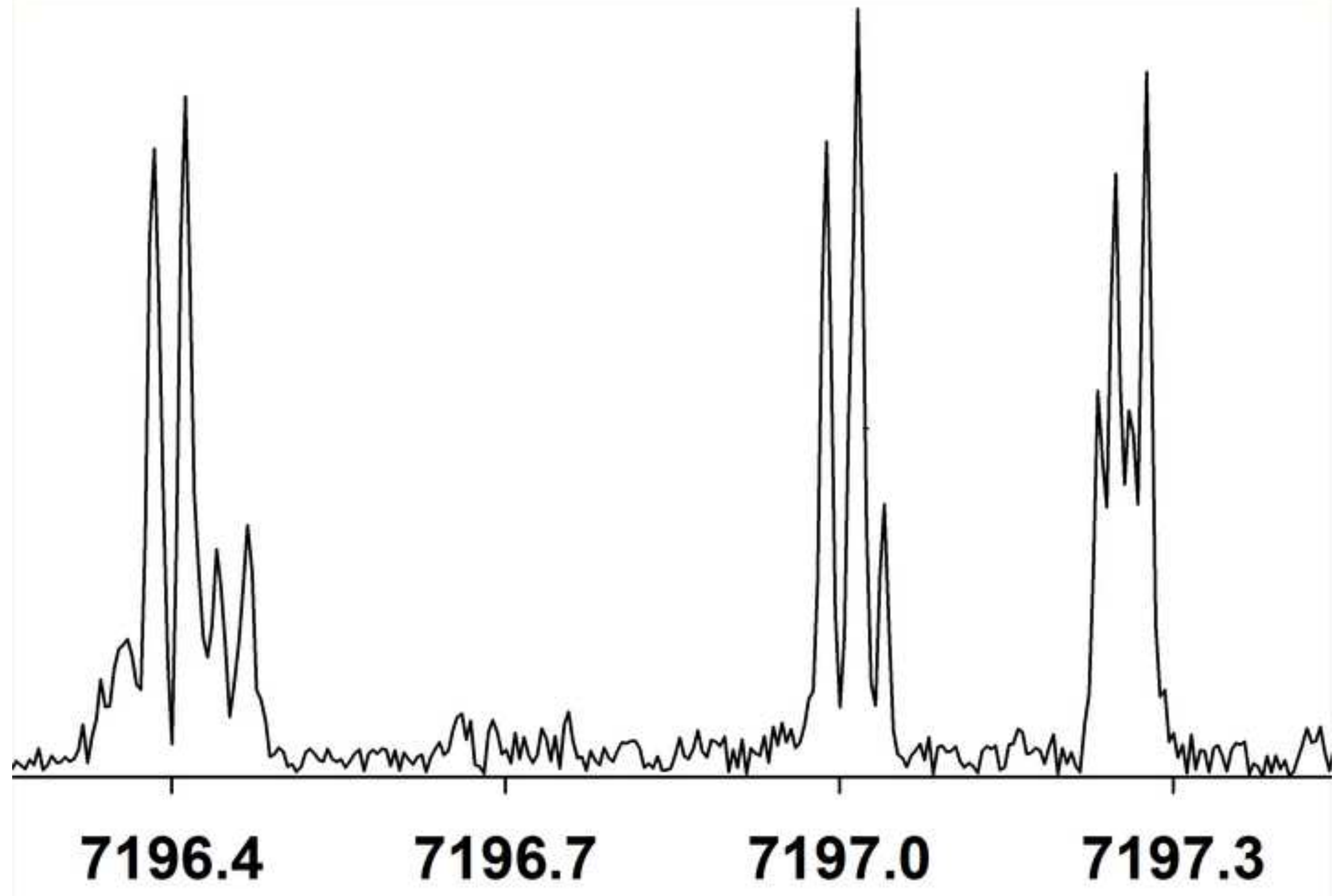




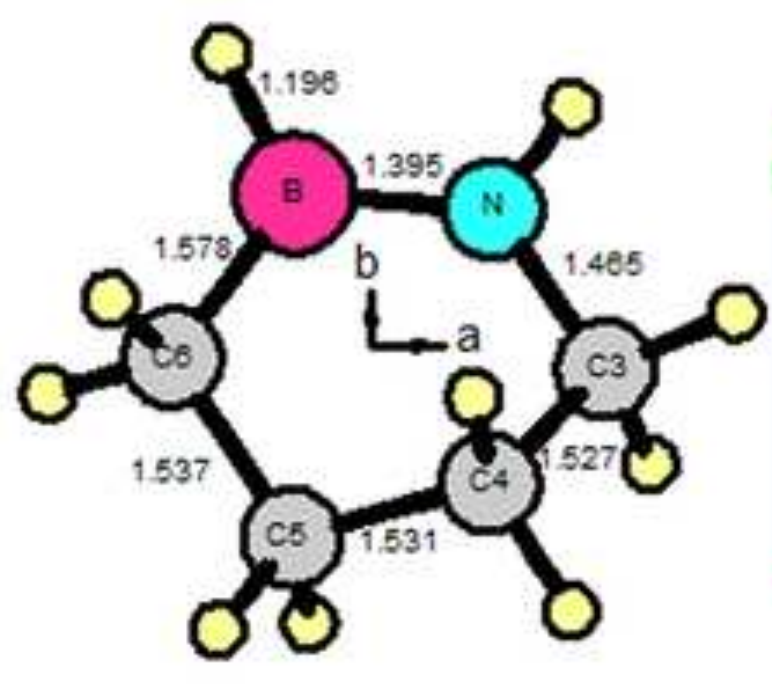

$\mathrm{BN}$-cyclohexene

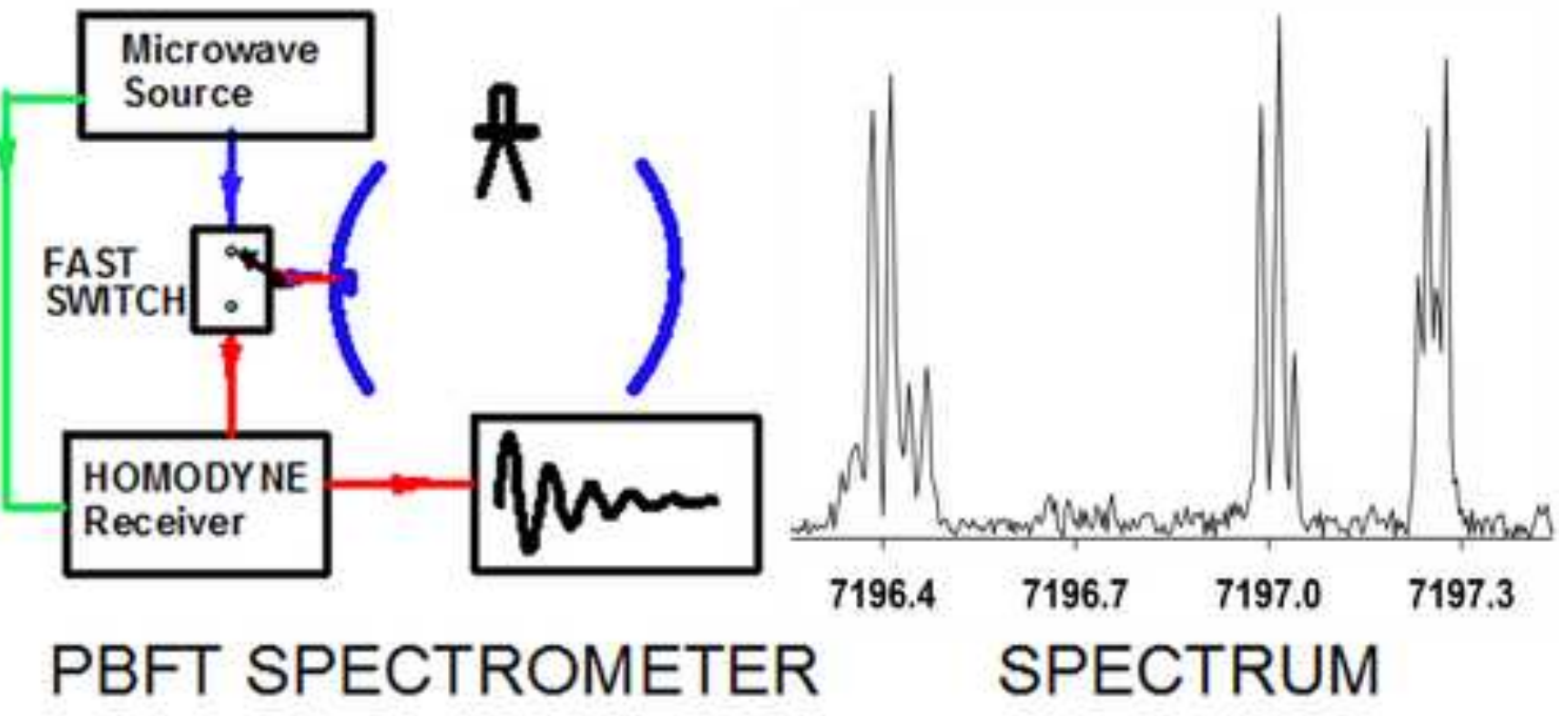

